Jurnal Artikel

\title{
Studi Prediksi Analitik Posisi Bantalan (Journal Bearing) Pada Turbin
} Gas

\author{
*Rizky Arman', Yovial Mahyoedin ${ }^{2}$ \\ ${ }^{1,2}$ Program Studi Teknik Mesin, Fakultas Teknologi Industri, Universitas Bung Hatta, Padang \\ *Email: rizky.arman@bunghatta.ac.id
}

Artkel Info - : Received : 14 Feb 2021; Revised : 20 Feb 2021; Accepted: 28 Feb 2021

\begin{abstract}
Abstrak
Bantalan menyediakan antarmuka utama antara bagian-bagian mesin yang bergerak dan tidak bergerak. Bantalan memberikan sebagian besar kekakuan dan redaman untuk struktur yang bergerak. Dapat dimengerti bahwa gaya dinamis yang dikembangkan pada bagian yang bergerak ditransmisikan ke bagian stasioner melalui bantalan penyangga utama ini. Gaya tersebut dapat berupa beban radial statis karena berat rotor, atau mungkin gaya dinamis karena mekanisme seperti ketidakseimbangan massa. Dalam kedua kasus tersebut, bantalan radial harus membawa beban yang diterapkan, atau mesin akan mengalami kegagalan. Dalam kebanyakan kasus, secara teknis sulit (jika bukan tidak mungkin) untuk secara langsung memeriksa validitas atau akurasi dari koefisien bantalan yang dihitung. Namun, setiap perhitungan harus diakhiri dengan keseimbangan gaya, ditambah keseimbangan posisi jurnal dalam jarak bebas bantalan. Karena jurnal dalam bantalan film-oli dapat diukur secara langsung dengan proximity probes, logis untuk melakukan pemeriksaan prediksi analitik versus data mesin yang sebenarnya. Proximity probe sensorik dipasang pada $\pm 45^{\circ}$ dari garis tengah vertikal sebenarnya. Pada bantalan ujung saluran masuk turbin \# 1, probe dipasang di atas poros. Sebaliknya, di exhaust \# 2 bantalan, probe terletak di bawah poros. Untuk penelitian pada kasus ini dilakukan pada empat turbin gas poros tunggal yang beroperasi antara 5.000 dan 5.350 RPM. Unit ini memiliki daya 40.000 HP, dan digunakan untuk menggerakkan kompresor sentrifugal bertekanan tinggi melalui satu kotak roda gigi heliks. Dapat dimengerti bahwa jika posisi eksentrisitas yang dihitung benar, maka parameter yang dihitung lainnya juga mewakili karakteristik bantalan.
\end{abstract}

Kata kunci: journal bearing, turbin gas, proximity probe, posisi eksentrisitas.

\begin{abstract}
Bearings provide the primary interface between the moving and the stationary parts of a machine. Although the seal and the process fluids (or magnetic fields) coexist, the bearings provide the majority of the stiffness and damping for the moving assembly. It is understandable that dynamic forces developed on the moving part are transmitted to the stationary part across these main support bearings. The forces may be the static radial loads due to the rotor weight, or they may be dynamic forces due to mechanisms such as mass unbalance. In either case, the radial bearings must carry the applied loads, or the machine will fail. In most cases, it is technically difficult (if not impossible) to directly check the validity or accuracy of the computed bearing coefficients. However, each calculation must conclude with a force balance, plus a position balance of the journal within the bearing clearance. For this case history, consider a group of four single shaft gas turbines that operate between 5,000 and 5,350 RPM. These units are rated at 40,000 HP, and they are used to drive high pressure centrifugal compressors through a single helical gear box. The shaft sensing proximity probes are mounted at $\pm 45^{\circ}$ from the true vertical centerline. At turbine inlet end\#1 bearing, the probes are mounted above the shaft. Conversely, at the exhaust end \#2 bearing, the probes are located below the shaft. Since journal within an oil film bearing can be measured directly with proximity probes, it is logical perform a check of the analytical prediction versus actual machine data. It is reasonable to believe that if the calculated eccentricity position is correct, than the other computed parameters are also representative of the bearing characteristics.
\end{abstract}

Keywords: journal bearing, gas turbine, proximity probes, eccentricity position. 


\section{PENDAHULUAN}

Bantalan digunakan untuk mencegah gesekan antar bagian selama gerakan relatif. Dalam permesinan mereka terbagi dalam dua kategori utama: bantalan antigesekan atau elemen gelinding dan bantalan jurnal hidrodinamik. Fungsi utama bantalan adalah untuk membawa beban antara rotor dan casing dengan keausan sesedikit mungkin. Fungsi bantalan ini ada di hampir setiap kejadian dalam kehidupan sehari-hari mulai dari jam tangan di pergelangan tangan Anda hingga mobil yang Anda kendarai hingga disk drive di komputer Anda. Dalam industri, penggunaan dikhususkan untuk mesin berputar baik kecepatan rendah maupun tinggi [1], [2].

Fluid film bearing adalah bantalan biasa yang paling banyak journal bearing digunakan. Bantalan ini mengandalkan viskositas pelumas untuk memisahkan permukaan bantalan. Poros yang berputar menyeret pelumas ke sekeliling sehingga membentuk baji pendukung. Bantalan ini juga biasanya membutuhkan sistem pelumasan. Pelumasan terus menerus bekerja untuk mendinginkan bantalan yang memungkinkan kecepatan poros tinggi dan beban berat.

Mesin industri dengan daya dan beban tinggi, seperti turbin uap, kompresor sentrifugal, pompa dan motor, menggunakan journal bearing sebagai penyangga rotor. Salah satu tujuan dasar bantalan adalah menyediakan lingkungan tanpa gesekan untuk mendukung dan memandu poros yang berputar. Dipasang dan dirawat dengan benar, journal bearing pada dasarnya memiliki umur yang tidak terbatas.

Dalam kebanyakan kasus, secara teknis sulit (jika bukan tidak mungkin) untuk secara langsung memeriksa validitas atau akurasi dari koefisien bantalan yang dihitung. Namun, setiap perhitungan harus diakhiri dengan keseimbangan gaya, ditambah keseimbangan posisi jurnal dalam jarak bebas bantalan..

\section{DESAIN BANTALAN}

Journal bearing sederhananya adalah silinder yang mengelilingi poros dan diisi dengan sejenis pelumas fluida. Dalam bantalan ini fluida adalah media yang menopang poros yang mencegah kontak logam ke logam. Cairan yang paling umum digunakan adalah oli, dengan aplikasi khusus yang menggunakan air atau gas. Catatan aplikasi ini akan berkonsentrasi pada bantalan jurnal berpelumas minyak [3], [4].

Prinsip hidrodinamik, yang aktif saat poros berputar, menciptakan irisan oli yang menopang poros dan memindahkannya ke dalam jarak bebas bantalan. Dalam bantalan terbelah secara horizontal, baji oli akan mengangkat dan menopang poros, memindahkan garis tengah sedikit ke atas dan ke satu sisi ke posisi sikap normal di kuadran bawah bantalan. Sudut sikap normal akan tergantung pada arah putaran poros dengan putaran searah jarum jam dengan sudut sikap di kuadran kiri bawah. Pengaruh eksternal, seperti tekanan volute hidrolik pada pompa atau beban listrik generator dapat menghasilkan gaya relokasi tambahan pada sudut sikap poros dan posisi garis tengah.

Karakteristik tambahan journal bearing adalah redaman. Jenis bantalan ini memberikan lebih banyak redaman daripada bantalan elemen bergulir karena ada pelumas. Film pelumas yang lebih kental dan lebih tebal memberikan sifat redaman yang lebih tinggi. Saat redaman yang tersedia meningkat, stabilitas bantalan juga meningkat. Desain bantalan yang stabil menahan rotor pada sudut sikap tetap selama periode transien seperti penyalaan/ penghentian mesin atau perubahan beban. Sifat redaman pelumas juga menyediakan media yang sangat baik untuk membatasi transmisi getaran. Dengan demikian, pengukuran getaran yang dilakukan pada kulit terluar bantalan tidak akan mewakili getaran aktual yang 
dialami oleh rotor dalam jarak bebas bantalannya.

Permukaan bagian dalam bantalan dilapisi dengan bahan yang lebih lembut, biasa disebut babbit. Babbit, yang merupakan paduan berbahan dasar timah atau timah, memiliki ketebalan yang dapat bervariasi dari 1 hingga 100 mils tergantung pada diameter bantalan. Lapisan babbit memberikan permukaan yang tidak akan merusak atau mencungkil poros jika terjadi kontak dan untuk memungkinkan partikel di pelumas tertanam di lapisan tanpa merusak poros.

Bantalan jurnal memiliki banyak desain berbeda untuk mengimbangi kebutuhan beban yang berbeda, kecepatan mesin, biaya, atau sifat dinamis. Satu kelemahan unik yang menghabiskan banyak penelitian dan eksperimen adalah ketidakstabilan yang memanifestasikan dirinya sebagai pusaran minyak dan cambuk minyak. Jika tidak diperbaiki, fenomena ini merupakan bencana besar dan dapat menghancurkan bantalan dan rotor dengan sangat cepat. Beberapa desain yang umum digunakan adalah lemon bore, pressure dam, dan bantalan bantalan kemiringan. Desain ini dikembangkan untuk menghentikan dan mengarahkan jalur aliran oli di dalam bantalan untuk memberikan stabilitas bantalan yang lebih tinggi.

Bantalan jurnal yang dipasang pada mesin industri saat ini umumnya terbagi dalam dua kategori: bantalan penuh dan bantalan busur parsial. Bantalan penuh sepenuhnya mengelilingi jurnal poros dengan banyak geometri yang berbeda seperti konfigurasi elips, lobed, atau bendungan tekanan dan biasanya dua bagian, dikawinkan pada garis split. Bantalan busur parsial memiliki beberapa permukaan bantalan beban individu atau bantalan dan terdiri dari banyak komponen yang dapat disesuaikan [5], [6].

Penggunaan bantalan jurnal juga merupakan keuntungan dalam banyak aplikasi dalam hal perawatan. Sebagian besar bantalan film fluida terbelah dan pelepasan rotor tidak diperlukan untuk memeriksa dan mengganti. Meskipun bantalan elemen gelinding terpisah juga tersedia, harganya mahal dan tidak umum. Kerusakan akibat kelelahan bantalan jurnal biasanya terlihat pada tahap awal dan memungkinkan diagnostik mode kegagalan yang lebih baik sehingga tindakan korektif dapat diambil untuk mencegah terulangnya kembali. Rentang operasi untuk berbagai jenis bantalan ditunjukkan pada Gambar 1.

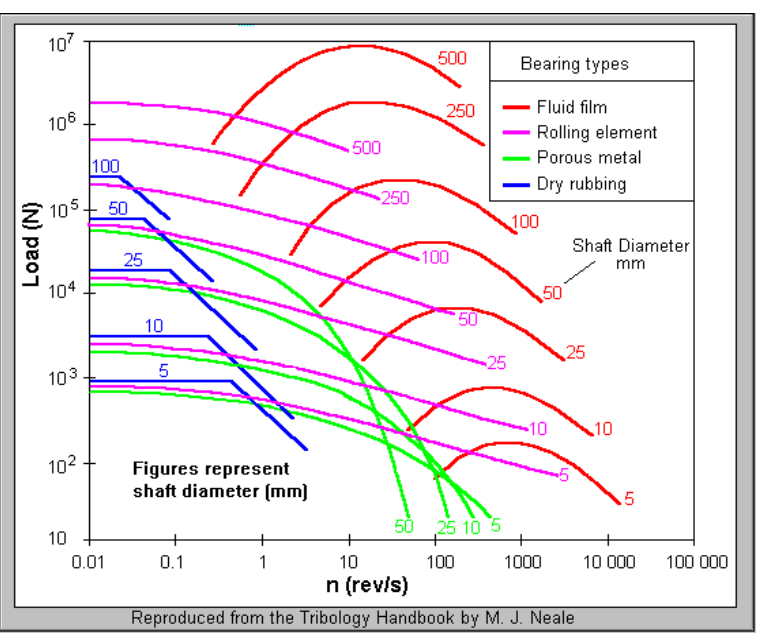

Gambar 1. Rentang operasi berbagai jenis bantalan

\section{METODE PENELITIAN: (Static And Dynamic Load Carrying Capacity)}

Dalam analitik pengembangan model mesin, selalu ada ketertarikan untuk memulai proyek dengan analisis rotor yang mendetail. Namun, ahli diagnosa mesin segera menemukan bahwa karakteristik bantalan harus ditentukan dan disertakan dalam model rotor. Dalam beberapa kasus, seperti optimalisasi sistem mekanis, berbagai jenis bantalan dapat dipertimbangkan dengan model rotor yang berbeda. Oleh karena itu, seringkali merupakan prosedur berulang untuk menentukan kombinasi bantalan dan konfigurasi rotor yang tepat. Salah satu titik awal yang paling mudah dan informatif adalah penentuan beban poros statik pada bidang planar bantalan [7], [8].

Peringkat Beban Statis Dasar yang diberikan untuk setiap bantalan dalam 
katalog bantalan didasarkan pada gaya aksial dan radial stasioner yang bekerja pada bantalan. Ketika bantalan dikenakan beban radial dan aksial, beban statis yang setara harus ditemukan sebagai berikut:

$\mathrm{Po}=\mathrm{Xo.Fr}+\mathrm{Yo.Fa}$, (1)

If only radial forces act then;

$\mathrm{Po}=\mathrm{Fr}$,

Dimana:

$P o=$ The equivalent static bearing load $(N)$

$F r=$ static radial load on the bearing $(N)$

$F a=$ static axial load on the bearing $(N)$

$X o=$ static radial factor

$Y o=$ static axial factor

(The values of $X o \& Y o$ are given in the Bearing Data). The Basic Static Load Rating $C o$ can be calculated from:

Co $=$ So.Po

Dimana:

Co = basic load rating $(N)$ So = static safety factor $P o=$ equivalent static bearing load $(N)$

Nilai So tergantung pada jenis bantalan dan persyaratan terkait pengoperasian. Jika bantalan diam dalam waktu lama atau berputar perlahan dan terkena beban kejut, maka prosedur pemilihan bantalan didasarkan pada peringkat beban dasar ini. Nilai Co untuk setiap bantalan dikutip dalam katalog bantalan. Pilih bantalan yang nilai kuotasinya untuk Co sama dengan nilai $C o$ yang diperlukan yang dihitung di atas, dan faktor keamanan statis ditunjukkan pada Tabel 1.

Tabel 1. Panduan nilai faktor keamanan statik

\begin{tabular}{cccccccc}
\hline & \multicolumn{2}{c}{$\begin{array}{c}\text { noise } \\
\text { unimportant }\end{array}$} & \multicolumn{2}{c}{$\begin{array}{c}\text { normal } \\
\text { running }\end{array}$} & \multicolumn{2}{c}{$\begin{array}{c}\text { quite } \\
\text { running }\end{array}$} \\
\cline { 2 - 8 } & ball & roller & ball & roller & ball & roller \\
\hline $\begin{array}{c}\text { smooth } \\
\text { loading }\end{array}$ & 0.5 & 1 & 1 & 1.5 & 2 & 3 \\
$\begin{array}{c}\text { normal } \\
\text { loading } \\
\text { shock } \\
\text { loading }\end{array}$ & 0.5 & 1 & 1 & 1.5 & 2 & 3.5 \\
\hline
\end{tabular}

Daya dukung beban dinamis suatu bantalan bergantung pada gaya dinamis yang bekerja pada bantalan serta gaya statis dasar. Oleh karena itu, langkah pertama adalah menghitung peringkat beban statis sebelum melanjutkan dengan prosedur berikut. Jika bantalan terkena gaya radial dan aksial maka beban bantalan dinamis yang setara harus dihitung:

$P=X F r+Y F a$

$P=$ The equivalent dynamic bearing load $(N)$

$F r=$ static radial load on the bearing $(N)$

$F a=$ static axial load on the bearing $(N)$ $X \quad=$ radial factor $Y=$ axial factor

When $F a=0$ or $F a$ is relatively small up to a limiting case of $F a / F r=e$ (where e is a certain limiting value) then:

$P=F r$

(The values of $X, Y \& e$ are given in the Bearing Data)

Setelah nilai untuk beban bantalan dinamis ekuivalen diperoleh, nilai tersebut dapat digunakan untuk menghitung peringkat beban dinamis bantalan. Nilai ini digunakan untuk memilih bantalan. Setiap bantalan dalam katalog bantalan memiliki nilai kutipan untuk peringkat beban dinamis dan oleh karena itu bantalan harus dipilih yang memiliki peringkat lebih tinggi dari yang dihitung. Peringkat beban dinamis yang dikutip dalam katalog untuk setiap bantalan bergantung pada umur bantalan yang diperlukan dan beban bantalan dinamis ekuivalen $(P)$. Persamaan ISO untuk umur rating dasar adalah:

$L_{10}=\left(\frac{C}{P}\right)^{p}$ or $C=P L_{10}{ }^{1 / p}$

Dimana:

$L=$ basic rated life, Millions of revolutions

$C$ =basic dynamic load rating $P=$ equivalent dynamic bearing load $p=$ exponent in the life equation ( 3 for 
all ball bearings and 10/3 for all other roller bearings)

Umur opeasi rata-rata (didefinisikan sebagai jumlah putaran yang diharapkan dapat dicapai oleh $90 \%$ dari kelompok bantalan identik) ditentukan dari lamanya umur yang diperlukan dari bantalan. Perkiraan umur operasi yang diharapkan dari berbagai mesin diberikan di bawah ini.

Tabel 2. Perkiraan umur rata-rata pemesinan

\begin{tabular}{lr}
\hline Machine Usage & Hours \\
\hline $\begin{array}{l}\text { intermittent- domestic machines } \\
\text { short periods- hand tools, } \\
\text { construction machines }\end{array}$ & $300-3000$ \\
high reliability for short periods- & \\
lifts, cranes & $3000-8000$ \\
8 h/day partial use gears, motors & \\
8 h/day full use machine tools, & $8000-12000$ \\
fans & $10000-25000$ \\
continuous use & $20000-30000$ \\
\end{tabular}

\section{HASIL DAN PEMBAHASAN}

Dalam kebanyakan kasus, secara teknis sulit (jika bukan tidak mungkin) untuk secara langsung memeriksa validitas atau akurasi dari koefisien bantalan yang dihitung. Namun, setiap perhitungan harus diakhiri dengan keseimbangan gaya, ditambah keseimbangan posisi jurnal dalam jarak bebas bantalan. Menjadi logis bahwa jika posisi eksentrisitas yang dihitung benar, maka parameter yang dihitung lainnya juga mewakili karakteristik bantalan. Karena jurnal dalam film-oil bantalan dapat diukur secara langsung dengan proximity probe, adalah penting untuk melakukan pemeriksaan prediksi analitik versus data mesin yang sebenarnya [1] [9], [10], [11].

Untuk riwayat kasus ini, pertimbangkan unit turbin gas poros tunggal yang beroperasi antara 5.000 dan 5.350 RPM. Unit ini memiliki daya $40.000 \mathrm{HP}$, dan digunakan untuk menggerakkan kompresor sentrifugal bertekanan tinggi melalui satu kotak roda gigi heliks. Sensor probe proximity poros dipasang pada $\pm 45^{\circ}$ dari garis tengah vertikal yang sebenarnya seperti yang ditunjukkan pada Gambar. 2. Pada bantalan ujung masuk turbin \# 1, probe dipasang di atas poros. Sebaliknya, di ujung exhaust \# 2 bantalan, probe ditempatkan di bawah poros [1].
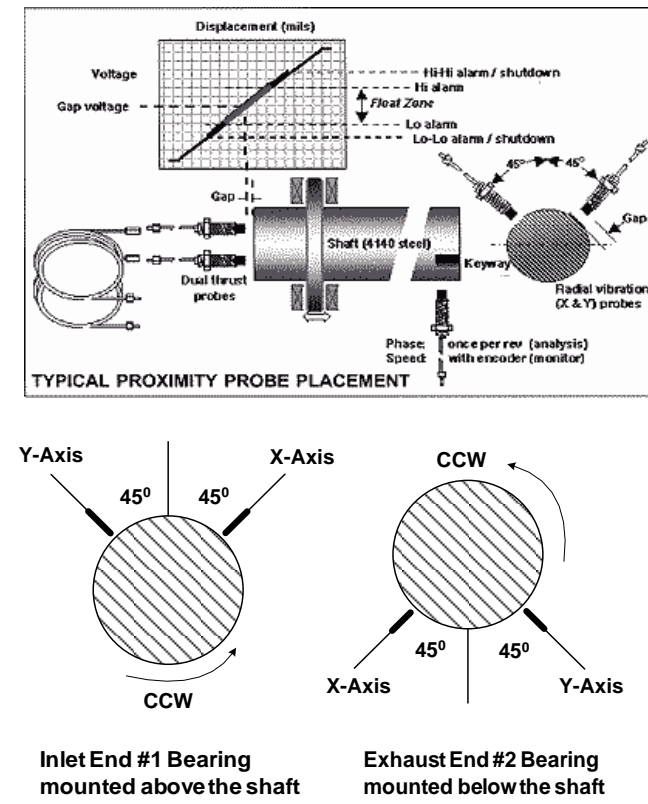

Gambar 2. Pengukuran dengan proximity probes pada poros

Jurnal berdiameter delapan inci didukung dalam bantalan elips. Bantalan ini memiliki jarak diametris vertikal ratarata 16 Mils (0,016 inci), dan jarak diameter horizontal normal 32 Mils. Dimensi fisik ini konsisten dengan jarak 2: 1.

Posisi garis tengah poros untuk jurnal mesin ini ditentukan dengan mengukur tegangan celah DC probe proximity pada kondisi berhenti, dan pada kecepatan penuh. Perbedaan antara tegangan DC ini dibagi dengan faktor skala transduser untuk menentukan perubahan posisi pada arah setiap transduser. Perubahan $X Y$ dalam posisi radial ini dapat diplot pada grafik yang menampilkan jarak bebas bantalan, ditambah posisi jurnal yang dihitung dalam arah $X$ dan $Y$ [12].

Gambar 3. menggambarkan posisi jurnal radial untuk bantalan masuk turbin. Lokasi garis tengah poros untuk unit A diperoleh pada tanggal yang berbeda, dan pada kecepatan yang sedikit berbeda bervariasi antara 5.100 dan 5.340 RPM. Tiga mesin tambahan yang diidentifikasi sebagai unit B, C, dan D juga disertakan 
dalam survei ini. Kecepatan untuk tiga unit terakhir ini bervariasi antara 5.010 dan 5.350 RPM. Tercatat bahwa ketetapan yang sangat baik telah dicapai antara posisi yang dihitung pada 5.340 RPM, dan enam set data lapangan.



$A-5,330$ RPM

A-5, 100 RPM

- A-5,340 RPM

A-5,350 RPM

A-5,010 RPM

A $A-5,30$ RPM

$\mathrm{X}$ Calculated

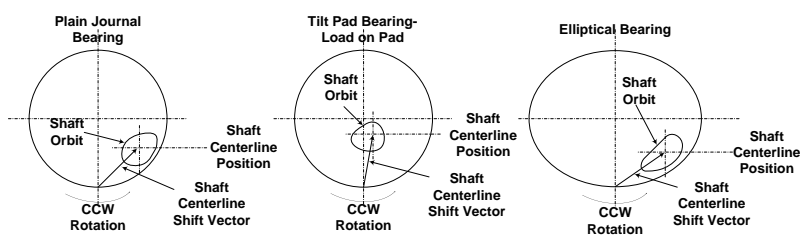

Gambar 3. Posisi centerline poros journal bearing pada inlet \#1

Informasi posisi yang sama untuk bantalan pada exhaust \# 2 seperti yang terdapat pada Gambar 4. Perhatikan bahwa sebaran data jauh lebih besar pada bantalan ini, dan penyimpangan dari posisi yang dihitung cukup besar. Awalnya, dapat disimpulkan bahwa teori tersebut tidak mendukung perilaku permesinan yang sebenarnya. Namun, sebagian penjelasan untuk penyimpangan ini berada dalam karakteristik probe proximity, dan driver pendamping yang peka terhadap suhu pengoperasian. Spesifikasi batas suhu untuk probe dan kabel khusus ini adalah $350^{\circ} \mathrm{F}$; dan batas operasi oscillatordemodulators ditentukan sebagai $150^{\circ} \mathrm{F}$ untuk unit standar, atau $212^{\circ} \mathrm{F}$ untuk versi rentang suhu yang diperpanjang.
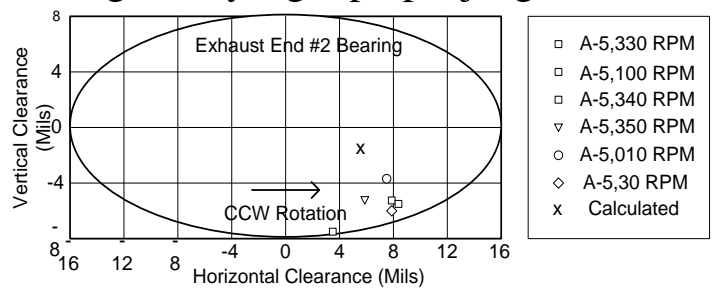

Gambar 4. Posisi centerline poros journal bearing pada exhaust \#2
Seperti yang ditunjukkan pada Gambar 2, probe pada exhaust dipasang di luar bantalan \# 2, dan di bawah garis tengah horizontal. Probe ini berada dalam lingkungan bersuhu tinggi yang dapat dengan mudah memanaskan transduser ke suhu yang melebihi $200^{\circ} \mathrm{F}$. Oscillatordemodulators dipasang pada ruang tahan ledakan. Meskipun pelindung panas dipasang di antara knalpot turbin dan boks ini, komponen listrik sering beroperasi pada suhu di atas $130^{\circ} \mathrm{F}$. Dengan demikian, probe pada ujung exhaust, kabel, dan driver semuanya terkena suhu tinggi yang memengaruhi kemiringan kurva kalibrasi.

Selama bertahun-tahun, vendor instrumentasi telah menyadari bahwa suhu pengoperasian akan mempengaruhi kalibrasi probe. Misalnya, Gbr. 5 menggambarkan variasi kurva kalibrasi pada suhu 75,200 , dan $350^{\circ} \mathrm{F}$. Data ini diterbitkan oleh pabrikan probe kedekatan yang dipasang pada turbin gas khusus ini. Data yang diplot adalah untuk probe berdiameter 0,300 inci. Ekskursi yang lebih besar biasanya ditunjukkan oleh ujung probe berdiameter lebih kecil. Dari kelompok kurva ini, jelas terlihat bahwa kurva kalibrasi akan membengkok ke bawah seiring kenaikan suhu. Pada $200^{\circ} \mathrm{F}$, kurva kalibrasi secara nominal 0,5 volt di bawah kurva normal untuk celah di sekitar $-9,0$ hingga $-10,0$ volt DC. Oleh karena itu, untuk jarak tertentu antara probe dan poros, tegangan DC keluaran dari Proximitor ${ }^{\circledR}$ berkurang sekitar 0,5 volt. Karena sistem pengukuran beroperasi dengan bias negatif, tegangan gap juga negatif. 


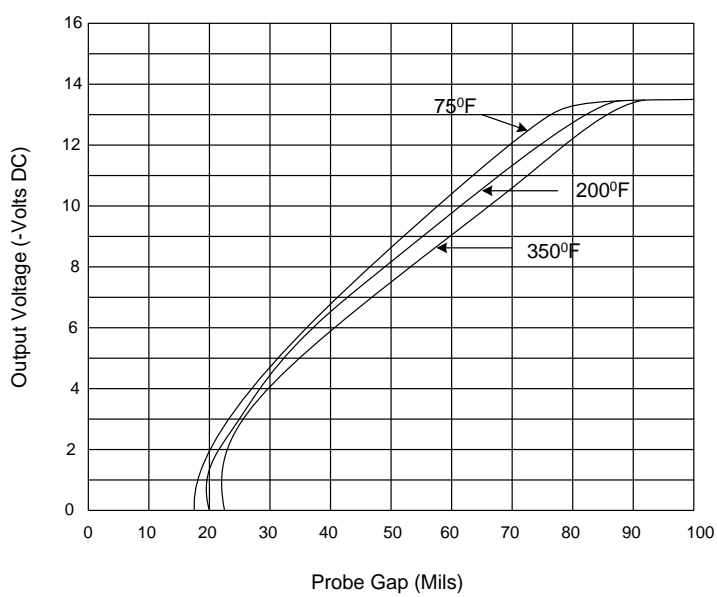

Gambar 5. Variasi kurva kalibrasi pada temperatur 75,200 , dan $350^{\circ} \mathrm{F}$

Koreksi untuk perilaku temperatur ini memerlukan penambahan tegangan ke tegangan keluaran Proximitor®. Jadi, tegangan DC keluaran yang diukur harus dikoreksi sebesar $-0,5$ volt DC untuk menghasilkan nilai kompensasi temperatur. Secara khusus, Tabel 3 merangkum tegangan gap dingin (saat berhenti), ditambah tegangan gap panas (berjalan) atau mesin B.

Tabel 3. Gap tegangan langsung proximity probe pada exhaust bantalan \#2

\begin{tabular}{ccccc}
\hline $\begin{array}{c}\text { Probe and } \\
\text { Angular Location }\end{array}$ & $\begin{array}{c}\text { Cold Gap } \\
\text { Voltage }\end{array}$ & $\begin{array}{c}\text { Hot Gap } \\
\text { Voltage }\end{array}$ & $\begin{array}{c}\text { Differential Gap } \\
\text { Voltage }\end{array}$ & $\begin{array}{c}\text { Differential } \\
\text { Position }\end{array}$ \\
\hline Y-Axis @3150 & -9.66 volts DC & -9.23 volts DC & +0.43 volts DC & +2.15 Mils \\
X-Axis @2250 & -9.23 volts DC & -10.47 volts DC & -1.24 volts DC & -6.20 Mils
\end{tabular}

Tegangan gap diferensial hanyalah tegangan dingin dikurangi tegangan gap panas pada exhaust bantalan turbin. Membagi tegangan celah diferensial probe sumbu-Y (vertikal) dengan sensitivitas transduser normal 0,2 Volt/Mil menghasilkan perubahan perpindahan 2,15 Mils ke arah probe. Demikian pula, transduser sumbu $\mathrm{X}$ (horizontal) menunjukkan perubahan $-1,24$ volt, yang setara dengan pergeseran posisi 6,20 Mil dari probe. Ini setara dengan pergeseran vektor poros keseluruhan sebesar 6,56 Mils pada $26^{0}$ dari posisi dingin ke posisi panas.

Namun, jika tegangan celah probe panas yang diukur dikoreksi sebesar -0,5 volt DC untuk mengimbangi sensitivitas suhu transduser, hasilnya ditunjukkan pada Tabel 4. Tegangan celah dingin awal (kecepatan nol) tetap sama seperti sebelumnya.

Pergeseran perpindahan sekali lagi ditentukan dengan membagi tegangan celah diferensial dengan 0,2 Volt/Mil untuk menentukan pergeseran jarak. Untuk probe sumbu $\mathrm{Y}$, ini menghasilkan perubahan perpindahan 0,35 Mils dari probe. Transduser sumbu $\mathrm{X}$ sekarang menampilkan perubahan $-1,74$ volt, yang sama dengan pergeseran posisi 8,70 Mil dari transduser. Pergeseran total posisi garis tengah jurnal oleh karena itu setara dengan pergeseran vektor 8,71 Mil pada $47^{0}$ (posisi dingin ke panas). Dengan demikian, koreksi suhu menunjukkan bahwa poros benar-benar naik lebih tinggi di bantalan daripada data yang tidak dikoreksi.

Tabel 4. Koreksi gap tegangan proximity probe pada bantalan turbin exhaust \#2

\begin{tabular}{ccccc}
\hline $\begin{array}{c}\text { Probe and } \\
\text { Angular Location }\end{array}$ & $\begin{array}{c}\text { Cold Gap } \\
\text { Voltage }\end{array}$ & $\begin{array}{c}\text { Hot Gap } \\
\text { Voltage }\end{array}$ & $\begin{array}{c}\text { Differential Gap } \\
\text { Voltage }\end{array}$ & $\begin{array}{c}\text { Differential } \\
\text { Position }\end{array}$ \\
\hline Y-Axis @315 & -9.66 volts DC & -9.73 volts DC & -0.07 volts DC & -0.35 Mils \\
X-Axis @2250 & -9.23 volts DC & -10.97 volts DC & -1.74 volts DC & -8.70 Mils \\
\hline
\end{tabular}

Koreksi masing-masing tegangan celah panas dari diagram garis tengah poros awal menghasilkan posisi jurnal yang disajikan pada Gambar 6. Sekali lagi, probe pada exhaust dipasang di bagian bawah poros, dan tegangan DC yang dikoreksi menunjukkan kenaikan posisi poros.

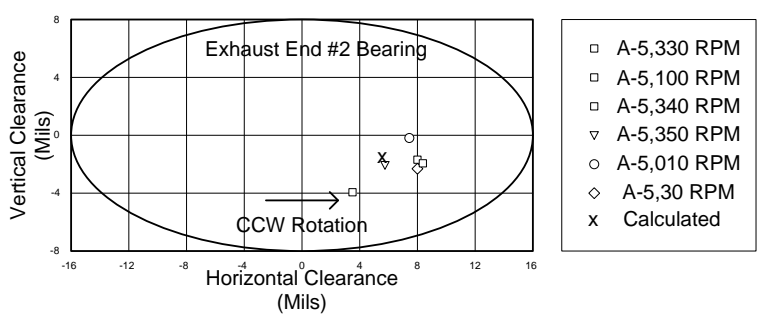

Gambar 6. Koreksi gap tegangan proximity probe pada bantalan turbin exhaust \#2 
Jelas bahwa ketetapan antara posisi jurnal yang dihitung dan diukur telah ditingkatkan secara signifikan dengan koreksi suhu celah probe sederhana ini. Penyimpangan yang tersisa dalam posisi radial terukur antara kedua ujung turbin sekarang dapat dikaitkan dengan adanya beban eksternal, momen, atau pengaruh lain yang bekerja pada poros.

Karena inlet \#1 bersebelahan dengan kopling aksesori, sedikit variasi torsi yang ditransmisikan selama operasi normal. Dengan demikian, adanya gaya eksternal, dan beban ketidaksejajaran minimal pada inlet bantalan. Seperti yang diamati sebelumnya, posisi yang diukur sangat sesuai dengan perhitungan teoritis yang hanya mempertimbangkan beban karena bobot jurnal yang diterapkan.

\section{KESIMPULAN}

Bagaimanapun juga pada exhaust bantalan turbin gas, keluaran daya penuh dari turbin disalurkan melalui kopling beban. Bergantung pada jenis kopling, posisi kesejajaran dan gaya eksternal terkait, lokasi jurnal yang sebenarnya mungkin akan menyimpang dari perkiraan eksentrisitas yang dihitung hanya dengan bobot jurnal. Nyatanya, pernyataan sebaliknya mungkin juga tepat. Artinya, karena posisi garis tengah poros ujung knalpot sesuai dengan lokasi yang dihitung, pengaruh gaya eksternal dapat dianggap minimal (yaitu, menunjukkan kopling Beban yang selaras dengan baik).

Secara keseluruhan, perhitungan eksentrisitas di kedua ujung turbin tampak realistis dan mewakili perilaku mesin ratarata. Korelasi antara posisi jurnal yang diukur, dan lokasi ekuilibrium terhitung dianggap mendukung keakuratan perhitungan analitik film fluida bantalan. Pengukuran dan perbandingan serupa dengan hasil yang dihitung dapat dilakukan pada kecepatan lain atau kondisi pasokan oli yang berbeda. Dalam kebanyakan kasus, harus ada korelasi yang baik antara posisi garis tengah poros yang diukur dan dihitung. Teknik ini juga dapat digunakan sebagai alat diagnostik. Misalnya, jika posisi operasi poros yang diukur sangat berbeda dari posisi yang dihitung, ahli diagnosa harus memberikan pertimbangan yang kuat tentang adanya beban awal poros internal atau eksternal.

\section{DAFTAR PUSTAKA}

[1] P. Pennacchi and A. Vania, "Analysis of the instability phenomena caused by steam in high-pressure turbines," vol. 18, pp. 593-612, 2011.

[2] M. E. Leader, "Understanding Journal Bearings."

[3] D. J. Salamone, "JOURNAL BEARING DESIGN TYPES AND THEIR APPLICATIONS TO TURBOMACHINERY by," pp. 179-190, 1984.

[4] "Bearing Supports from Automotion Components."

[5] M. He, C. H. Cloud, and J. M. Byrne, "FUNDAMENTALS OF FLUID FILM JOURNAL BEARING OPERATION AND MODELING," 2005.

[6] W. B. Rowe, K. Cheng, and D. Ives, "A knowledge-based system for the selection of fluid film journal bearings," Tribol. Int., vol. 24, no. 5, pp. 291-297, 1991.

[7] J. D. Irwin, Mechanical Engineer 's Handbook Academic Press Series in Engineering Series Editor. 2001.

[8] J. D. Irwin, Mechanical Engineer's Handbook. 2001.

[9] C. Jackson, "by,” pp. 73-86, 1960.

[10] G. F. Simmons, Journal Bearing Design, Lubrication and. 2013.

[11] K. R. Guy and D. A. Services, "11 Problems - 11 Solutions," no. March, pp. 16-22, 2007.

[12] J.D. McHugh, "principles of turbomachinery bearings.pdf." . 